\title{
Kinetic and Mechanistic Studies on the Formation of Number of 2-Pyrazoline Derivatives
}

\author{
Abdul Majeed M. Dabbagh* \\ ** Khozan A. Haji \\ *Department of Chemistry / College of Science / University of Mosul \\ ** Department of Chemistry/ College of Education / University of Salahaddin/ Erbil
}

(Received $30 /$ 10/2013; Accepted $30 / 12 / 2013$ )

\begin{abstract}
The kinetics of the addition of hydrazine to the double bond of some chalcones have been studied using UV-visible technique. The reaction is considered as a pseudo-first order process which includes a nucleophilic attack by hydrazine at the $\beta$-carbon of the $\alpha, \beta$-unsaturated carbonyl system to afford the expected heterocycle "pyrazoline".

The rate constants were found to depend on different variables such as variation of different substituents. Arrhenius parameters and entropy of activation for all reactions have been computed. A suitable mechanism which is consistent with the experimental results is suggested for the reactions.
\end{abstract}

Keywords : Kinetics of Pyrazolines, Hydrazines or Chalcones

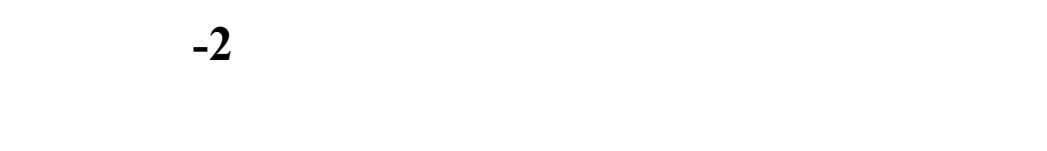

يتضمن البمث درلسة حركية إضفة الهايدرازين على الآصرة المزدوجة لبعض الجالكونت بلستخدلم فقية الأشعة فوق البفسجية - المرئية. وقد وجد بأن الفاعل هو من الفاعلات ذات الرتبة الأوله الوهمية، والتي تتضضمن الإضلفة النيكليوفيلية للهايدرازين على ذرة الكاربون بيتا لمظومة الكاربونيل الفا - بيتا غير المشبعة، لتنتج المركب الحلقي غير المتجانس "البايرازولين".

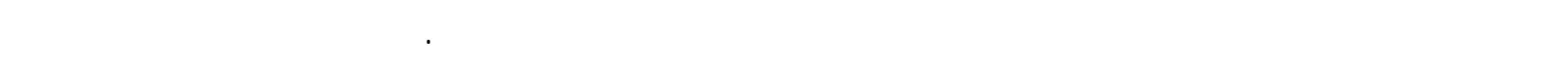
وانتروبي التنشيط لجمبع الفاعلات، مم اقترحت ميكانيكية منلسبة تنسهم مع النتائج العملية. الكامك الدالة : حركية البايرازولينت، الهايدرازين أوالجالكونات.

\section{INTRODUCTION}

Polarization (Ogata et al., 1968) of the $\alpha, \beta$-unsaturated ketones, afforded by the carbonyl group $(\mathrm{C}=\mathrm{O})$, will affect the $(\mathrm{C}=\mathrm{C})$ in such compounds and possibly lead to a nucleophilic addition (Michael or 1,4-addition) to the double bond, forming the less stable enol form, which in turn tautomerizes to the more stable keto form (Fazaeli et al., 2010; Levai et al., 2004; Sloop et al., 2008).

The present investigation is concerned with the kinetics of the addition of hydrazine to the $\alpha, \beta$ double bond of some chalcones and to study the effect of substituent in the phenyl ring of the chalcone on the stability of the presumed transition state, in order to obtain information that should be of assistance in understanding the suggested mechanism which occurs under mild conditions of experiments. 


\section{Materials}

\section{EXPERIMENT}

The hydrazine used was of analar grade as supplied by Fluka company, ethanol (Commercial scale) was purified and dried by $\mathrm{CaCl}_{2}$ until it became almost absolute. All chalcones under study were prepared in the Chemistry department, College of Education, Salahaddin University by standard procedure (Dabbagh and Aljuwari, 2013). All organic compounds used for the synthesis of chalcones were purified before use and identified using NMR, IR and UV-visible spectroscopy (Haji, 2013).

\section{Kinetic Measurements}

A spectrophotometric method was used to monitor the disappearance of the chalcone under study, using a Bio-Tek (model 99-90287 ) UV-Visible spectrophotometer under constant temperature by circulating water from a water bath type Gemmy Co. throughout a Teflon stopper double jacket quartz cuvette type $(62 / \mathrm{Q} / 10)$ using a Watson Marlow peristaltic pump at a constant speed of water circulation. All pipe connections were used with proper insulation to ensure the constant temperature of the reaction. Working solutions of $1 \times 10^{-3} \mathrm{M}$ hydrazine and $5 \times 10^{-5} \mathrm{M}$ chalcone were used in absolute ethanol as a solvent in a neutral medium at zero time. A blank cell containing $1 \times 10^{-3} \mathrm{M}$ hydrazine in absolute ethanol was used. All the kinetic data were processed on computer using Microsoft Excel (2010), Origin 6.1 and Get Data programs.

\section{RESULTS}

The reaction was found to be very slow. The kinetic measurements for the formation of the parent pyrazoline at $\lambda \max =275 \mathrm{~nm}$ indicated sa total second order reaction ; presumably first order with respect to each reactant when using 1:1 mixing mole ratio of reactants as shown in Fig. (1).

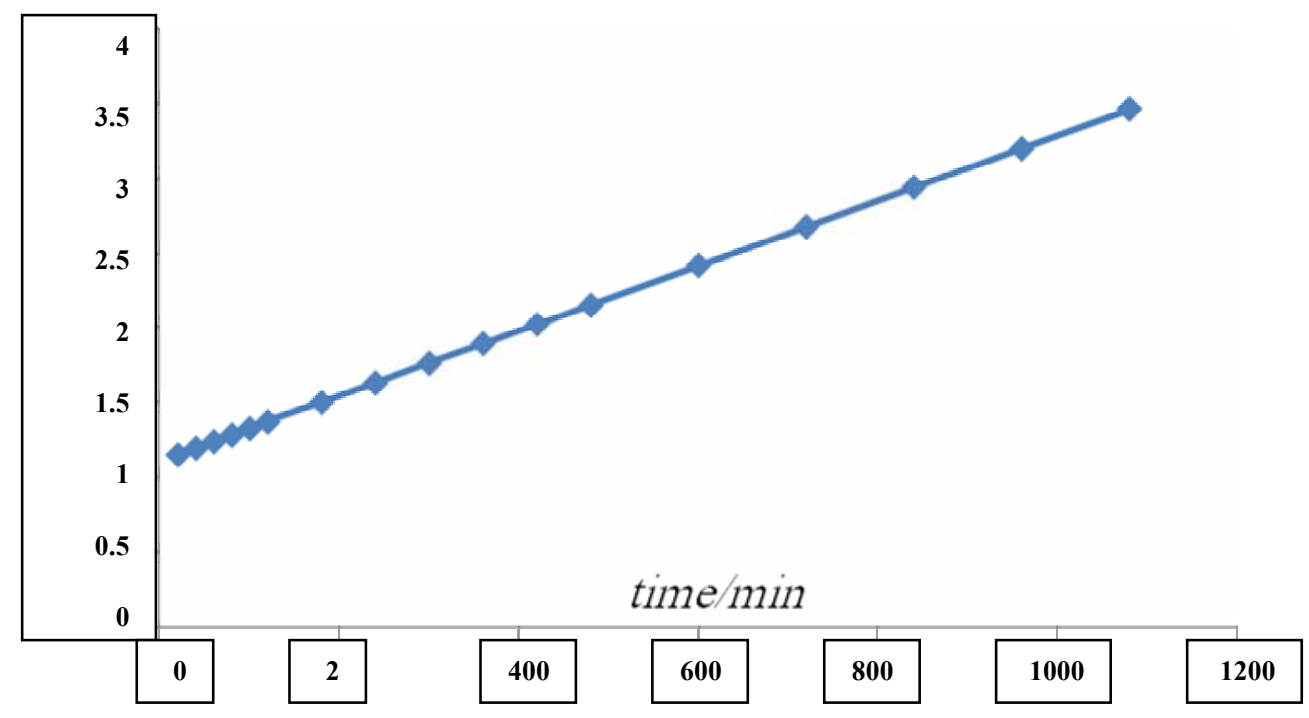

Fig. 1: Second order plot for the reaction of the parent chalcone (A) with hydrazine to form the pyrazoline in ethanol at $303 \mathrm{~K}$ using equimolar reactants ratio.

The study also showed a pseudo first order process for the disappearance of the reacting chalcone as shown in fig (2) using a mole ratio of (1:20) ([chalcone]: [hydrazine]) at $\lambda \max =(320-345 \mathrm{~nm})$. At this wave length the monitored reactant neither interfered with hydrazine, $(\lambda \max =212 \mathrm{~nm})$, nor with the corresponding pyrazoline, $\lambda \max =(275-285 \mathrm{~nm})$. The reaction was also monitored using a full scan UVVisible spectrum. No other products or side reactions were found and $\mathrm{A}_{\infty}$ of the chalcone always approached to zero indicating that no equilibrium process existed. The product structure was confirmed 
by IR and NMR spectra (Haji, 2013). These observations suggest that the addition reaction proceeds clearly according to the simple stoichiometry of reaction:
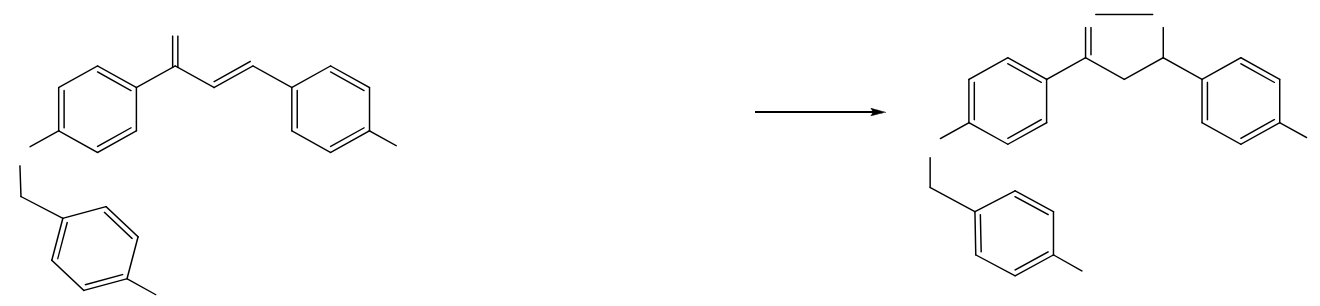

O

Substituent

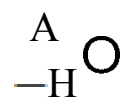

$\mathrm{B}$
$-\mathrm{OCH}_{3}$

$\mathrm{C}$
$-\mathrm{Cl}$<smiles>[Y]C([2H])(C)C</smiles>

$+\mathrm{NH}_{2} \mathrm{NH}_{2} \cdot \mathrm{H}_{2} \mathrm{O}$ $\mathrm{E}$ $-\mathrm{NO}_{2}$

Typical runs were performed for all chalcones with different substituents and the following integrated pseudo $1^{\text {st }}$ order equation in terms of absorption functions was used; plots were found to be linear for at least $85 \%$ of the reaction.

$$
\operatorname{Ln} \frac{A_{o}-A_{\infty}}{A_{t}-A_{\infty}}=k_{o b s .} t
$$

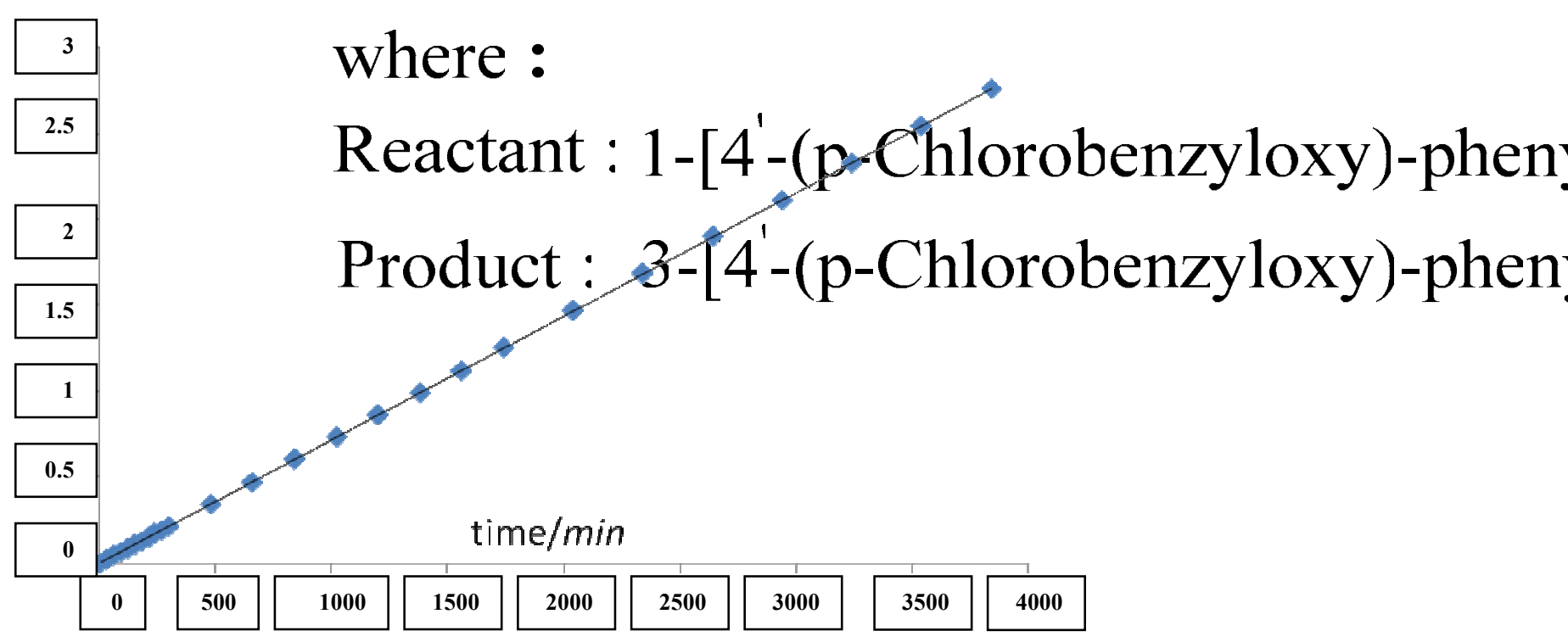

Fig. 2: Pseudo first order plot for the reaction of parent Chalcone (A) with hydrazine in ethanol at $298 \mathrm{~K}$

Measurements were carried out at different temperatures and the results are shown in (Table 1). 
Table 1: Observed rate constants for the reactions of different chalcones with hydrazine at different temperatures

\begin{tabular}{|c|c|c|c|c|c|}
\hline $\begin{array}{c}\text { Tem } \\
\text { p./ } \mathbf{K}\end{array}$ & \multicolumn{5}{|c|}{$\mathbf{1 0}^{4} \mathbf{k}_{\text {obs }} / \mathbf{m i n}^{-1}$} \\
& $-\mathbf{H ~ ( A )}$ & $-\mathbf{O C H}_{\mathbf{3}} \mathbf{( B )}$ & $-\mathbf{C l}(\mathbf{C})$ & $-\mathbf{C H}_{\mathbf{3}}$ (D) & $-\mathbf{N O}_{\mathbf{2}} \mathbf{( \mathbf { E } )}$ \\
\hline 288 & $6.22 \pm 0.03$ & $2.90 \pm 0.07$ & $9.11 \pm 0.10$ & $5.33 \pm 0.07$ & $18.20 \pm 0.10$ \\
\hline 298 & $7.20 \pm 0.03$ & $4.10 \pm 0.07$ & $10.50 \pm 0.11$ & $6.40 \pm 0.08$ & $19.90 \pm 0.12$ \\
\hline 308 & $8.19 \pm 0.03$ & $5.66 \pm 0.08$ & $12.00 \pm 0.12$ & $7.60 \pm 0.08$ & $21.70 \pm 0.14$ \\
\hline 318 & $9.35 \pm 0.04$ & $7.66 \pm 0.08$ & $13.60 \pm 0.12$ & $8.93 \pm 0.10$ & $23.50 \pm 0.11$ \\
\hline 328 & $10.50 \pm 0.04$ & $10.20 \pm 0.08$ & $15.30 \pm 0.13$ & $10.40 \pm 0.09$ & $25.40 \pm 0.12$ \\
\hline
\end{tabular}

Arrhenius plots were performed for all reactions; energies of activation, A-factors and entropies of activation were estimated as listed in (Table 2).

Table 2: Arrhenius parameters and entropies of activation for the reactions of different chalcones with hydrazine

\begin{tabular}{|c|l|l|c|c|c|}
\hline \multicolumn{2}{|c|}{ Substituted Chalcone } & $\mathbf{E a} / \mathbf{k J m o l}^{-1}$ & $\mathbf{r}^{2}$ & $\mathbf{1 0}^{4} \mathbf{A} / \mathbf{s}^{-1}$ & $\begin{array}{c}-\Delta S^{*} / \mathbf{J K}^{-1} \mathbf{m o l}^{-1} \\
\text { (at 298 K) }\end{array}$ \\
\hline A & $-\mathrm{H}$ & 10.287 & 0.9999 & 7.60 & 312.9 \\
\hline $\mathrm{B}$ & $4-\mathrm{OCH}_{3}$ & 24.620 & 0.9998 & 14.40 & 269.5 \\
\hline $\mathrm{C}$ & $4-\mathrm{Cl}$ & 10.190 & 0.9994 & 10.70 & 310.1 \\
\hline $\mathrm{D}$ & $4-\mathrm{CH}_{3}$ & 13.122 & 0.9993 & 21.29 & 304.4 \\
\hline E & $4-\mathrm{NO}_{2}$ & 6.550 & 1.0000 & 4.67 & 317.0 \\
\hline
\end{tabular}

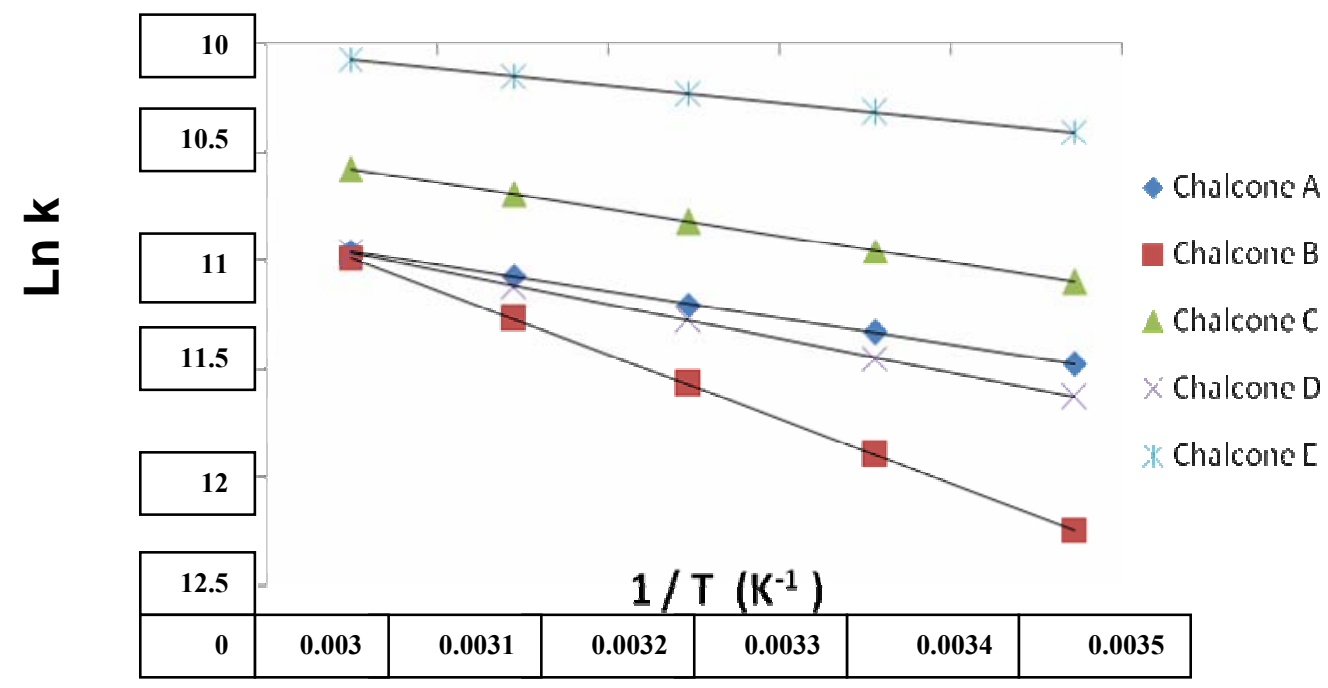

Fig. 3: Arrhenius plots for the reaction of chalcones (A-E) with hydrazine 
For chalcones (A-E), the electronic effects of the substituents play an important role in affecting the rate of reaction, since they either enrich or pauperize the reaction centre at the $\alpha$, $\beta$-double bond with electrons.

The differences in rates of reaction were found to be in the following order:

$$
\mathrm{E}\left(\mathrm{p}-\mathrm{NO}_{2}\right)>\mathrm{C}(\mathrm{p}-\mathrm{Cl})>\mathrm{A}(\mathrm{H})>\mathrm{D}\left(\mathrm{p}-\mathrm{CH}_{3}\right)>\mathrm{B}\left(\mathrm{p}-\mathrm{OCH}_{3}\right)
$$

As shown in Table (1), this sequence of arrangements indicates that electronic effects play an important role in enhancing the rate of reaction or reducing it in comparison with the parent chalcone A. It is found that for $\mathrm{D}$ and $\mathrm{B}$ the $\mathrm{p}-\mathrm{OCH}_{3}$ and $\mathrm{p}-\mathrm{CH}_{3}$ groups respectively are electron donating groups, thus enrich the reaction centre at the $\beta$-carbon with electron density and increase the repulsive forces with the hydrazine nucleophile. As a result the rate of reaction is reduced, Table (1). On the other hand, electron withdrawing groups such as $\mathrm{p}-\mathrm{NO}_{2},(\mathrm{E})$, and $\mathrm{p}-\mathrm{Cl},(\mathrm{C})$, groups reduce the electron density at the reaction centre, $\beta$ carbon, resulting in a partially positive reaction centre; thus providing a better chance for the hydrazine nucleophile to attack, and relative acceleration of reaction rates are achieved. From these observations, it can be concluded that the condensation process of the various chalcones with hydrazine proceeds via a nucleophilic addition reaction mechanism, (Sloop et al., 2008).

The values of activation parameters are of great importance to discern the mechanism under all the circumstances studied here. The energies of activation for all reactants are generally small in value and vary between $(6.5-24.6) \mathrm{kJ} / \mathrm{mol}$. Which may be attributed to the electron donating or withdrawing capabilities of the attacked centre. Their values come in line with as discussed above, i.e. a fast reaction requires low $E_{a}$ and vice versa. This observation is also explicable with the attack of the nucleophile to the partially positive reaction centre. It is noticed that the value of the activation energy of the p-chloro substituent $(10.2 \mathrm{~kJ} / \mathrm{mol}$.), is very close to the value of the parent chalcone A. This is unsurprising since the chloro group carries a simultaneous dual characters, resonance and inductive effects (Smith and March, 2007).

The other important factors that must be taken into consideration are the A-factor and its corresponding entropy of activation $\Delta \mathrm{S}^{\#}$. These two factors, in addition to the activation energy control the reaction rate (Connors, 1990). All the values of A-factors obtained in this study are extremely less than $10^{13.5} \mathrm{~s}^{-1}$ ( which corresponds to $\Delta \mathrm{S}^{\#}=0$ according to the activation complex theory), resulting in a large negative entropy of activation. The decrease in the value of A-factor provides an important indication about the stability of the intermediate and hence gives a good support for explaining the reason of the differences in the values of rate constants. The negative value of the $\Delta S^{\#}$ of the reactions indicates the formation of a restricted intermediate which suffers from a lack of certain degrees of freedom as compared to the reactants.

The negative value of $\Delta S^{\#}$ of the reaction of parent chalcone $A$,

( $-312.9 \mathrm{JK}^{-1} \mathrm{~mol}^{-1}$ ), as shown in Table (2) is compared with the substituted analogues (B,C,D and E). It can be concluded that the electronic effect plays an important role in the stabilization of the formed intermediate. It is quite likely that the p-methoxy group in chalcone B increases the probability of building up a negative charge at the reaction centre, hence increases the probability of repulsive forces between the chalcone and the hydrazine nucleophile leading to a loose structure of the intermediate with a relatively higher value of $\Delta \mathrm{S}^{\#}\left(-269.5 \mathrm{JK}^{-1} \mathrm{~mol}^{-1}\right)$. On the other hand, the relative lower value of $\Delta \mathrm{S}^{\#}\left(-317.0 \mathrm{JK}^{-1} \mathrm{~mol}^{-1}\right)$ for the p-nitro group in chalcone $\mathrm{E}$, indicates that this group is a good electron withdrawing group since it decreases the probability of finding electrons at the reaction centre, hence increases the probability of attractive forces between the chalcone and the hydrazine nucleophile leading to the formation of a rigid structure of the intermediate similar to the cyclic form of 
the pyrazoline with a lower value of $-\Delta S^{\#}$. The value of the p-chloro substituent in chalcone $C$ is very close to the value of parent chalcone A which probably indicates that this group possesses equally donor and accepter character.

The same discussion may also be applied to reactions of chalcones $\mathrm{D}\left(-304.4 \mathrm{JK}^{-1} \mathrm{~mol}^{-1}\right)$ and B $\left(-269.5 \mathrm{JK}^{-1} \mathrm{~mol}^{-1}\right)$ which show that the $\mathrm{p}-\mathrm{OCH}_{3}$ group provides the reaction centre with more electron density than $\mathrm{p}-\mathrm{CH}_{3}$ and elevates the value of $\Delta \mathrm{S}^{\#}$ due to the increase in repulsive forces between the chalcone and the nucleophile; thus leads up to the formation of a looser transition state in comparison with chalcone $\mathrm{B}$ (with $\mathrm{p}-\mathrm{CH}_{3}$ ).

From these investigations, it can be concluded that an electronic effect plays an important role in the stabilization of the formed transition state. Also the reaction of the chalcone with the hydrazine nucleophile proceeds via the formation of a relatively slow step despite the low activation energy .

The rate constant values, the Arrhenius parameters values as well as the negative values of activation entropies are in a quite agreement with the following suggested mechanistic route.

1- Fast step: Nucleophilic attack by hydrazine at the $\beta$-carbon of the $\alpha, \beta$-unsaturated carbonyl system, followed by proton transfer from nitrogen to form an enol-keto tautomers.
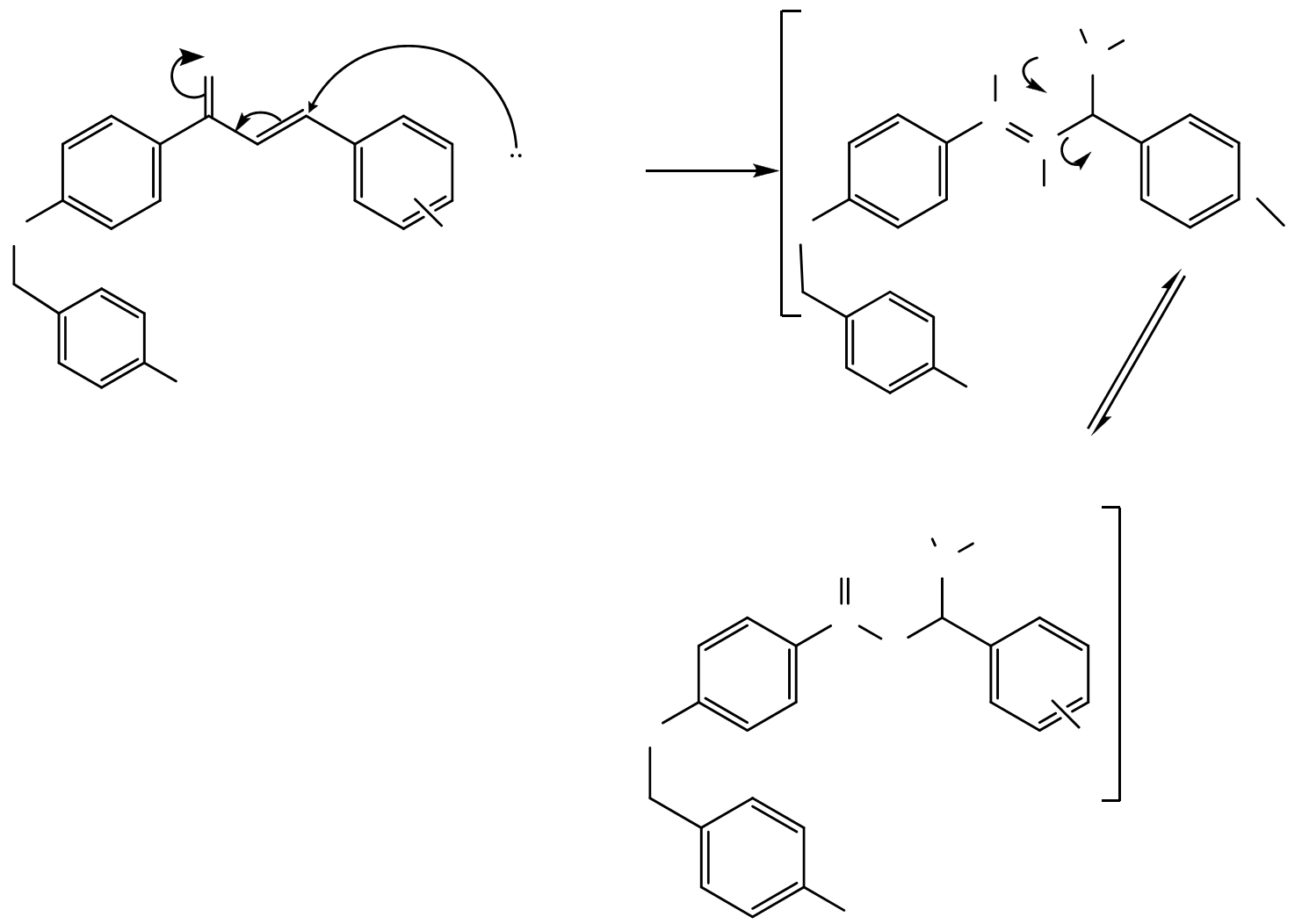

2- Slow step: A unimolecular cyclization process resulted by the intramolecular nucleophilic attack by the primary amine on its carbonyl carbon followed(by proton transfer from nitrogen to oxygen. 


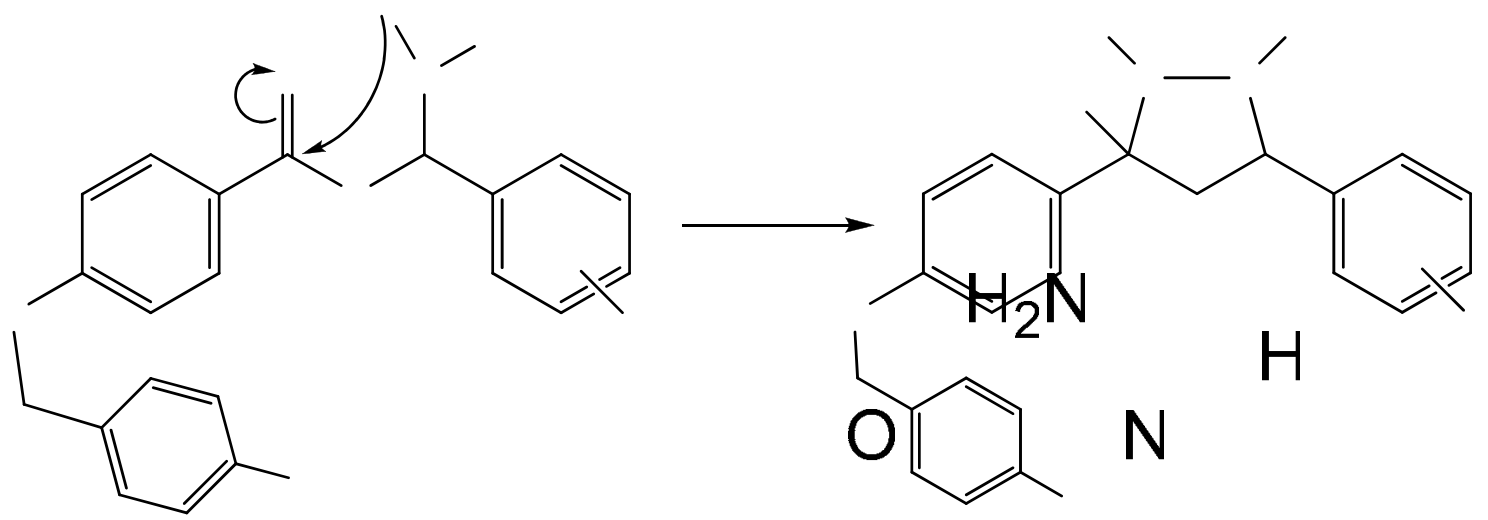

3- Fast step: Loss of water molecule to yield pyrazoline (product).

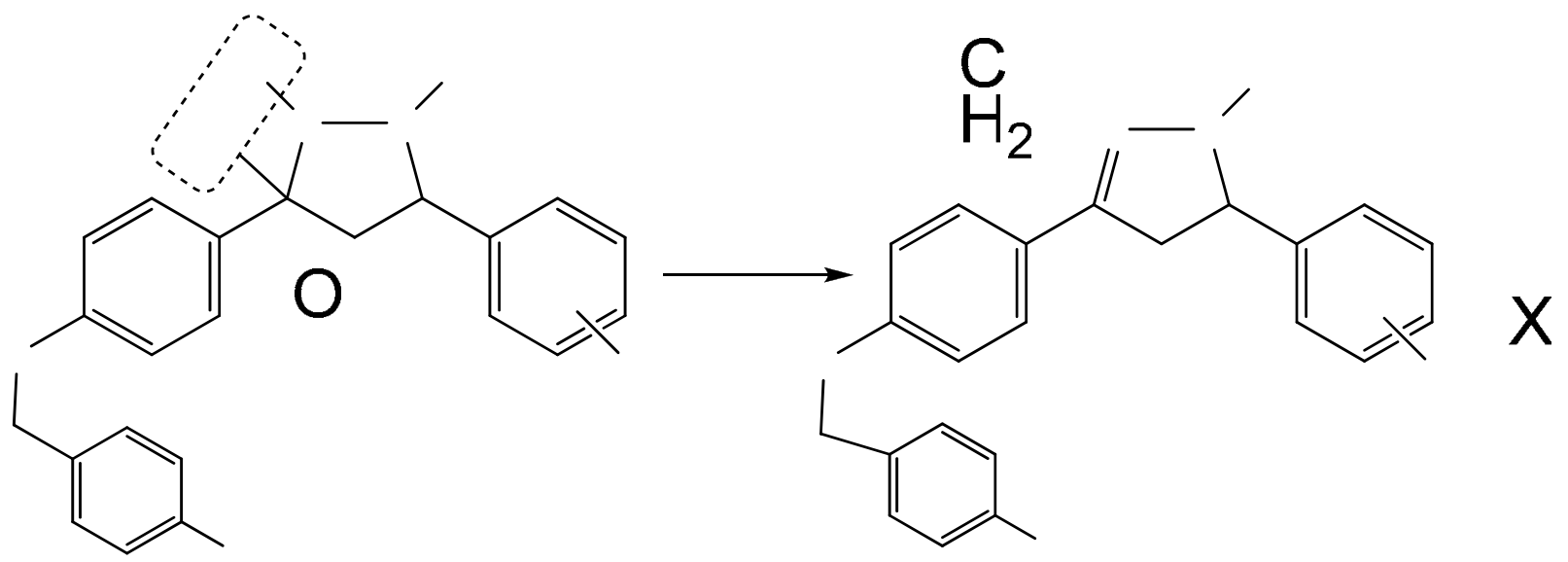

REFERENCES

Connors, K.A. (1990). "Chemical Kinetics". VCH Pub., 13 p.

Dabbagh, A.M.; Aljuwari, S.S. (2013). Kinetics and mechanistic studies of the bromination of some derivatives of 1,3-diaryl-2-propen-1-one. Raf. J. Sci. 24(1), 50-59.

Fazaeli, R.; Aliyan, H.; Bordbar, M.B.; Mohammadi, E. (2010). Highly efficient catalysts for the synthesis of novel 1,3,5-Triaryl-2-Pyrazoline derivatives. The Open Catalysis J., 3,79.

Haji, Kh.A. (2013). Kinetics and mechanistic studies on the formation of some $\alpha, \beta$-unsaturated ketones in different solvents and their reactions with bromine and hydrazine. Ph. D. thesis, College of Education, Univ. of Salahaddin, pp. 238-247.

Levai, A.; Silva, A.M.S.; Pinto, D.; Cavaleiro, J.A.; Alkorta, I.; Elguero, J.; Jeko, J. (2004). Synthesis of chlorinated 3,5-diaryl-2-pyrazolines by the reactior $\mathbf{N}$ f chloroc $\mathbf{A l c o n e s}$ with hydrazines. Eur. J. Org. Chem., 2, 4672.

$\mathrm{HO}$

Ogata, Y.; Sawaki, Y.; Gotoh, S. (1968). Polarization of $\alpha, \beta$-unsaturated ketones. J. Amer. Chem. Soc. 19, 241.

Sloop, J.C.; Lechner, B.; Washington, G.; Bumgardner, C.L.; Loehle, W.D.; Creasy, W. (2008). Pyrazole formation: examination of kinetics, substituent effects, and mechanistic pathways. Int. J. Chem. Kinetics, 40,7, 370.

Smith, M.B.; March, J. (2007). "March's Advanced Organic Chemistry: Reactions, Mechanisms, and Structure ". $6^{\text {th }}$ edition, John Wiley \& Sons, pp. 999,1000,1002. 